\title{
Highly toughened polylactide with epoxidized polybutadiene by in-situ reactive compatibilization
}

\author{
Yanshai Wang, Zhiyong Wei, Xuefei Leng, Kaihua Shen, Yang Li* \\ State Key Laboratory of Fine Chemicals, Key Laboratory of Polymer Science and Engineering of Liaoning \\ Province, Liaoning Engineering Laboratory of Advanced Polymer Materials, Department of Polymer Science and \\ Engineering, Faculty of Chemical, Environmental and Biological Science and Technology, Dalian University of \\ Technology, Dalian 116024
}

\begin{abstract}
Relatively high contents of rubber are commonly required to trigger the brittle-to-ductile transition when using rubber components to toughen polylactide (PLA). However, the strength may drop remarkably after incorporation of large amount of rubber. The main motivation of the present work is to achieve a good toughness-strength balance in a PLA/rubber system with less amount of rubber phase $(90 / 10 \mathrm{w} / \mathrm{w})$. In this study, polybutadiene (PB) was used to toughen PLA due to the flexible molecular chains. In attempt to enhance the compatibility of PB in PLA matrix, epoxidized polybutadiene (EPB) with different epoxidation degree were prepared by an in situ peroxy-formic acid method. The compatibility, phase morphologies, mechanical properties and thermal properties of the PLA/EPB blends were investigated respectively. It was found that epoxy group of EPB showed a significant effect in enhancing compatibility between rubber phase and PLA matrix, giving rise to a remarkable decrease in the particle diameter of rubber phase. When both of the good compatibility and the appropriate particle size of the rubber phase were realized, the impact toughness of PLA/EPB blend was improved by 13 times for that of pure PLA, while the tensile strength still preserved as a level of $77 \%$ (based on the value of pure PLA). The interfacial compatibilization between PLA and EPB was achieved through the formation of graft-copolymer being a compatibilizer caused by the in-situ reaction between EPB and PLA in the melt blend process. This result proves the introduction of active groups into PLA blends to be a platform to design their performance via regulating the phase structure.
\end{abstract}

Keywords: Polylactide; Epoxidized polybutadiene; Compatibility 


\section{Introduction}

Polylactide (PLA) is a well-known biodegradable and bioabsorbable, renewably derived polymer. It has attracted so much attention due to the environmental concerns and sustainability issues associated with petroleum-based polymers. It performs outstanding physics and mechanical properties and holds great potential as an alternative to petroleum-based polymer materials. Unfortunately, the poor toughness and brittle nature limit its use in the applications that need plastic deformation at higher stress levels (e.g. screws and fracture fixation plates) [1-3]. Over the past several years, many strategies have been employed to improve the mechanical toughness of PLA, such as processing manipulation, introducing a rubber phase in block copolymer and blending with flexible materials [4-16]. Among these methods, blending PLA with flexible materials is probably the most effective and industrial practical for commercial applications.

Although numerous attempts have been made to toughen PLA through blending, the focus has typically been on the use of biodegradable polymers as second-phase polymers, because they offer property improvements without compromising biodegradability, such as poly(3-hydroxy butyrate) (PHB) and its copolymers[17, 18], polycaprolactone (PCL)[19, 20], poly(butylene adipate-co-terephthalate) (PBAT) and poly[(butylene succinate)-co-adipate] (PBSA)[21]. The tensile and impact properties have been improved somewhat, but not enough as the engineering plastics. Moreover, the price of a biodegradable polymer is very high due to its limited sources of raw materials. PLA/non-biodegradable polymer blends are also used in toughening PLA, like linear low-density polyethylene (LLDPE) [22], hydrogenated styrene-butadiene-styrene block copolymer (SEBS)[23], acrylonitrile-butadiene-styrene (ABS)[24], ethylene-n-butylacrylate-glycidyl methacrylate (EBA-GMA)[7, 25], poly(butylenessuccinate-co-adipate)[26], poly(b-hydrox-ybutyrate-co-b-hydroxyvalerat)[27], expoxidized natural rubber (ENR)[12], glycidyl methacrylate grafted poly(ethylene octane)[28]and polymerized soybean oil[29]. For both PLA/biodegradable and PLA/non-biodegradable blends, relatively high contents of flexible polymer is required to blend with PLA and the toughness is improved while the tensile strength and modulus are tremendous decrease[30]. In addition, most polymer blends are thermodynamically immiscible due to the low entropy of mixing, and the poor interface would easily result in premature interfacial failure and hence rapid and catastrophic crack propagation through the whole material, thus, a third component is often introduced as a compatibilizer[31]. To get the excellent toughness-strength balance, less flexible polymer component and an effective strategy for dramatically improving the toughness are expected.

The effectiveness of rubber toughened plastics is controlled by many factors such as type and blend ratio of rubber, size and shape of the rubber phase, interfacial adhesion between rubber 
particles and matrix, blending methods, processing condition, etc [12, 14-16, 32-34]. Generally, rubber components with lower $T_{\mathrm{g}}$ are preferred. As we know, the $T_{\mathrm{g}}$ of polybutadiene $(\mathrm{PB})$ is around $-90{ }^{\circ} \mathrm{C}$, and it is considered to be the best toughening agent for polystyrene: the impact strength of polystyrene can be increased from $13-25 \mathrm{~J} / \mathrm{m}$ up to $50-400 \mathrm{~J} / \mathrm{m}$ by incorporation $\mathrm{PB}$ into the polystyrene matrix $[30,35]$. Due to its advantages of high toughness, outstanding mechanical strength, PB seems to be a good toughening agent for PLA. Our attention in this study is paid to a blending system of PLA resin with low content (about $10 \mathrm{wt} \%$ ) of PB rubber. However, for such blending system, PB tends to be phase separation from PLA due to the non-polarity of PB and polarity of PLA, and the increment in toughness is very limited. Therefore, copolymers premade or formed in-situ is required to compatibilize PLA matrix and PB. In this study, we attempt to use a chemical-modified PB which may react with PLA to form an in-situ graft-copolymer in melting process. In that case, the blend could have high interfacial adhesion between the plastic matrix and the dispersed phase (the rubber particles).

Epoxidized polybutadiene (EPB) with different epoxidation degree were prepared firstly by reacting $\mathrm{PB}$ with peroxide and then used as the toughening agent. On the one hand, the compatibility could be enhanced because the polarity of EPB was higher than PB. On the other hand, epoxide groups have been reported as reactive groups with PLA (reaction between the epoxide groups and the terminal carboxyl and hydroxyl groups of PLA)[12, 35-37]. So graft-copolymer may be created at the interface between the two phases which acts as a compatibilizer. In the present work, an as-prepared epoxidized polybutadiene is selected to improve the compatibility between PLA matrix and rubber phase, and to modify the mechanical properties by regulating the phase morphology. Furthermore, the compatibility, phase morphologies, mechanical and thermal properties of the blends were investigated in details.

\section{Experimental}

\section{Materials}

All polymers used are commercial grade. Polylactide (PLA) resin of 4032D was from NatureWorks (USA). Polybutadiene (PB) was from Asahi Kasei Corporation (Japan), with $M_{\mathrm{n}}=10.6 \times 10^{4} \mathrm{~g} / \mathrm{mol}$, $\mathrm{IP}=1.23$. Toluene, tetrahydrofuran (THF), hydrogen peroxide $\left(\mathrm{H}_{2} \mathrm{O}_{2}\right)(30 \mathrm{wt} \%)$, formic acid $(88$ wt \%), chloroform-d $\left(\mathrm{CDCl}_{3}\right)$ and methanol were purchased from commercial sources without further purification.

\section{Preparation of EPB}

The PB was epoxidized to furnish a functional PB containing randomly distributed epoxy groups on the backbone chain, as shown in Scheme 1. Typically, EPB was prepared as follows: PB (10.0 g) 
and toluene $(300 \mathrm{~mL})$ were mixed in a $500 \mathrm{~mL}$, round-bottom flask equipped with a magnetic stirring bar. The reaction mixture was heated to $25^{\circ} \mathrm{C}$ and then formic acid $(3.4 \mathrm{~g})$ was added with stirring. Aqueous $30 \mathrm{wt} \% \mathrm{H}_{2} \mathrm{O}_{2}$ solution was then added dropwise to the mixture over a period of 15 $\min$. The reaction was allowed to proceed for $15 \mathrm{~h}$ at $25^{\circ} \mathrm{C}$. After the reaction, the organic phase was washed with distilled water until the washings were neutral; the product was precipitated in methanol and subsequently dried under vacuum at $40{ }^{\circ} \mathrm{C}$ overnight.

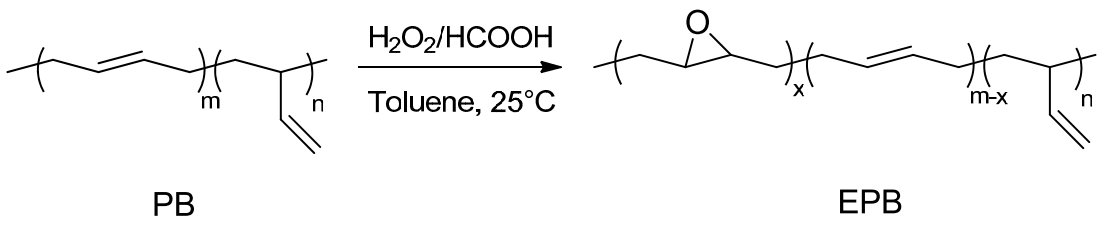

Scheme 1. Synthesis scheme of EPB.

\section{Preparation of the blends}

Prior to blending, the PLA, PB and EPB were separately dried at $80{ }^{\circ} \mathrm{C}$ and $40{ }^{\circ} \mathrm{C}$ for at least $12 \mathrm{~h}$ in a vacuum oven. In this research, the concentration of the rubbers in the blends was fixed at 10 $\mathrm{wt} \%$. All the blends were prepared in a Haake internal melt mixer (PolyLab OS, Germany) at a rotor speed of $60 \mathrm{rpm}, 170{ }^{\circ} \mathrm{C}$ for $10 \mathrm{~min}$. The well mixed blends were cut into small granules. Pure PLA was treated with the same procedure for comparison. Throughout the article the blends will be referred to as PLA/PB or PLA/EPB with a number representing the epoxidation degree of EPB, for instance: PLA/EPB6.4\% for the blend of PLA with EPB with a $6.4 \%$ epoxidation degree, PLA/PB for the blend of PLA with virgin PB.

\section{Structure characterization}

${ }^{1} \mathrm{H}$ NMR spectra was obtained on an Advance (Bruker Co., Ltd., Germany) $400 \mathrm{MHz} \mathrm{NMR}$ spectrometer at ambient temperature with $\mathrm{CDCl}_{3}$ as solvent. Fourier transform infrared (FTIR) spectra were recorded on Nicolet IS5 spectrometer using KBr pellets.

\section{Rheological measurements}

The dynamic rheological properties of the pure PLA, PLA/PB and PLA/EPB were assessed using a rotational rheometer, (TA, AR2000ex, USA) at $190{ }^{\circ} \mathrm{C}$. Parallel plate geometry with a diameter of $25 \mathrm{~mm}$ and a gap of $1 \mathrm{~mm}$ was adopted. A dynamic frequency sweep test was performed to determine the rheological properties of the samples. During the test, the frequency scanned from 0.01 to $100 \mathrm{~Hz}$ was used with strain controlled in $1 \%$.

\section{Morphology observation}

The morphologies of the pure PLA, PLA/PB and PLA/EPB were investigated with a scanning electron microscope (SEM). Before the SEM observation, samples were immersed in liquid nitrogen for $30 \mathrm{~min}$ and immediately fractured to expose the internal structures, then samples were 
submerged in THF for 5 min. Before the SEM observation, all the samples were sputtered with gold.

\section{Mechanical properties}

All the samples for Izod impact tests and tensile tests were prepared by an injection molding machine (RAY-RAN3400, England). Average value of five repeats was taken for each sample. The bar specimens of $63.7 \mathrm{~mm} \times 12.7 \mathrm{~mm} \times 3.17 \mathrm{~mm}$ were made with a $\mathrm{V}$ notch depth $2.5 \mathrm{~mm}$ according to ASTM D256. Notched Izod impact tests were performed using an impact test machine (CEAST9050, Italy). Dumbbell specimens having stripe part of $2 \mathrm{~mm}$ thickness and $4 \mathrm{~mm}$ width were stretched at a cross speed of $10 \mathrm{~mm} / \mathrm{min}$ at room temperature using a tensile tester (Instron5567A, USA) according to ISO 527-1. To study the fracture mechanism of the blends, the Izod fractured surfaces were observed with SEM. Before the SEM observation, all the surfaces were sputtered with gold.

\section{Thermal analysis}

The glass transition temperature for the PB and EPB were studied by a DSC instrument (TA, Q2000, USA). Samples (about $10 \mathrm{mg}$ ) were taken into an aluminum pan and sealed tightly with an aluminum cover. The samples were cooled down from room temperature to $-120{ }^{\circ} \mathrm{C}$, then isothermal for 2 minutes, finally heated to $40{ }^{\circ} \mathrm{C}$. All the heating and cooling rates were $10{ }^{\circ} \mathrm{C} / \mathrm{min}$. The glass transition temperature $\left(T_{\mathrm{g}}\right)$ was obtained from the DSC curves.

The DSC data for the pure PLA, PLA/PB and PLA/EPB were recorded by another DSC instrument (TA, Q20, USA). Samples were prepared as describe above. Firstly, the samples were heated from room temperature to $190{ }^{\circ} \mathrm{C}$ to eliminate heat history. Secondly, cooled down to $105{ }^{\circ} \mathrm{C}$ and annealed at this temperature for isothermal crystallization for $60 \mathrm{~min}$ and then cooled down to $0{ }^{\circ} \mathrm{C}$. Finally, the samples were reheated up to $190{ }^{\circ} \mathrm{C}$. All the heating and cooling rates were $10{ }^{\circ} \mathrm{C} / \mathrm{min}$. The glass transition temperature $\left(T_{\mathrm{g}}\right)$, cold crystallization temperature $\left(T_{\mathrm{c}}\right)$ and melting temperature $\left(T_{\mathrm{m}}\right)$ were obtained from the DSC curves. The crystallinity $\left(\% X_{\mathrm{c}}\right)$ of PLA in the PLA, PLA/PB and PLA/EPB was obtained from the DSC data by using the following equation:

$\% X_{\mathrm{c}}=\left[\Delta H_{\mathrm{m}} / \Delta H_{\mathrm{m}}^{0}\right] / \Phi_{\mathrm{PLA}} \times 100 \%$

where $\Delta H_{\mathrm{m}}$ was the melting enthalpies of PLA. $\Phi_{\mathrm{PLA}}$ was the weight fraction of PLA in the blends and $\Delta H_{\mathrm{m}}^{0}$ was the reference $\Delta H_{\mathrm{m}}(93.6 \mathrm{~J} / \mathrm{g})$ for PLA crystals having $100 \%$ crystallinity.

The thermal stability of the samples (about 10mg) was investigated with a TGA instrument (TA, Q500, USA) under nitrogen atmosphere. The samples were heated from room temperature to $600{ }^{\circ} \mathrm{C}$ at a heating rate of $10{ }^{\circ} \mathrm{C} / \mathrm{min}$. The onset decomposition temperature $\left(T_{\mathrm{d} 0}\right), 5 \%$ weight loss temperature $\left(T_{\mathrm{d} 5 \%}\right)$, fastest decomposition temperature in stage $1\left(T_{\mathrm{d} 1}\right)$ and fastest decomposition 
temperature in stage $2\left(T_{\mathrm{d} 2}\right)$ of the samples were obtained from the TGA curves.

\section{Dynamic mechanical analysis (DMA)}

Dynamic mechanical properties of the blends were measured using a DMA (TA, Q800, USA) under a single-cantilever strain-controlled mode with an oscillating amplitude of $15 \mu \mathrm{m}$ and frequency of $1 \mathrm{~Hz}$. The temperature was swept from $-120{ }^{\circ} \mathrm{C}$ to $150{ }^{\circ} \mathrm{C}$ at $3{ }^{\circ} \mathrm{C} / \mathrm{min}$. The test sample size was $17.2 \mathrm{~mm}$ (length) $\times 7.5 \mathrm{~mm}($ width $) \times 3.2 \mathrm{~mm}$ (thickness) .

\section{Results and discussion}

\section{Characterization of EPB}

Synthesis of epoxidized PB was carried out by an in situ peroxy-formic acid method. Fig. 1 shows the ${ }^{1} \mathrm{H}$ NMR spectra of the virgin PB and the EPB. The chemical shifts at $\delta=2.7$ and 2.9 were assigned to the cis-epoxy hydrogens and trans-epoxy hydrogens. The epoxidation degree $(E)$ was calculated as following equation [38]:

$$
E=\frac{A_{\delta=2.7}+A_{\delta=2.9}}{A_{\delta=2.7}+A_{\delta=2.9}+A_{\delta=5.4}+A_{\delta=5.0}-\frac{1}{2} A_{\delta=5.0}} \times 100 \%
$$

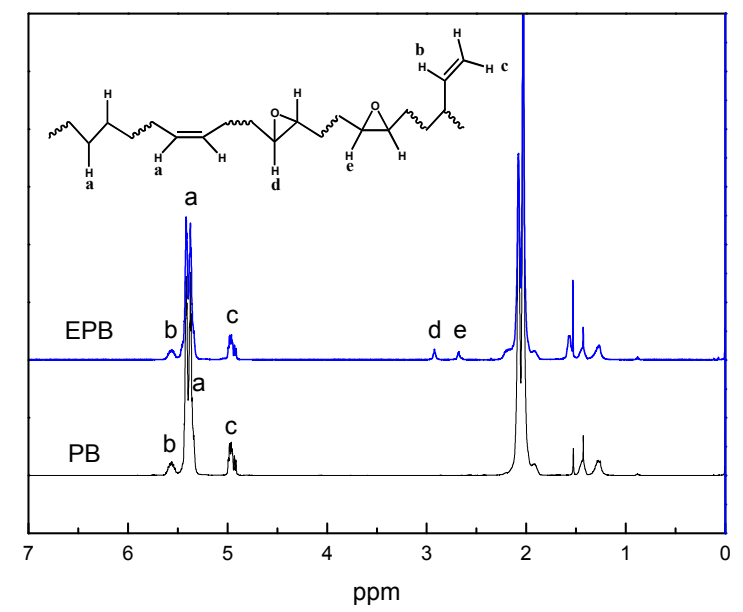

Fig. $1{ }^{1} \mathrm{H}$ NMR spectrum of PB and EPB.

In this epoxidation system, the epoxidation degree was designed by the amount of hydrogen peroxide. As shown in Table $1, E^{\text {actual }}$ was much lower than $E^{\text {theory }}$, which was; only part of hydrogen peroxide had reaction with the double bond of $\mathrm{PB}$ under the experiment conditions. $E^{\text {actual }} / E^{\text {theory }}$ was defined as the epoxidation efficiency $(f)$, and it was stabilized between $0.60-0.65$. The oxidation efficiency could not reach $100 \%$, because the macromolecular chains tangled in solution. The glass transition temperature for the PB and EPB was shown in Fig. 2 and Table 1. DSC results showed that the $T_{\mathrm{g}}$ of $\mathrm{PB}$ was $-91.3{ }^{\circ} \mathrm{C}$, with increase the epoxidation degree from 0 to $46.5 \%$, the $T_{\mathrm{g}}$ 
increased significantly by about $43{ }^{\circ} \mathrm{C}$ (from -91.3 to $-48.4{ }^{\circ} \mathrm{C}$ ). We obtained the relationship between $T_{\mathrm{g}}$ and $E: T_{\mathrm{g}}(\mathrm{K})=0.91 \times E+181.3$ by linear fitting method, as shown in Fig. 3 .

Table 1 Characterization of PB and EPB.

\begin{tabular}{ccccc}
\hline Samples & $E^{\text {theory a }}$ & $E^{\text {actual }}$ & $f$ & $T_{\mathrm{g}},{ }^{\circ} \mathrm{C}$ \\
\hline PB & 0 & 0 & - & -91.3 \\
EPB6.4\% ${ }^{\mathrm{b}}$ & $10 \%$ & $6.4 \%$ & 0.64 & -85.5 \\
EPB12.4\% & $20 \%$ & $12.4 \%$ & 0.62 & -80.9 \\
EPB20.9\% & $32 \%$ & $20.9 \%$ & 0.65 & -73.7 \\
EPB29.2\% & $45 \%$ & $29.2 \%$ & 0.65 & -66.2 \\
EPB46.5\% & $77 \%$ & $46.5 \%$ & 0.60 & -48.4 \\
\hline
\end{tabular}

${ }^{\mathrm{a}} E^{\text {theory }}=n\left[\mathrm{H}_{2} \mathrm{O}_{2}\right] / n$ [double bond] $\times 100 \%$.

${ }^{\mathrm{b}}$ The EPB refers to as EPB with a number representing the epoxidation degree, for instance: EPB6.4\% means the epoxidation degree of EPB is $6.4 \%$.

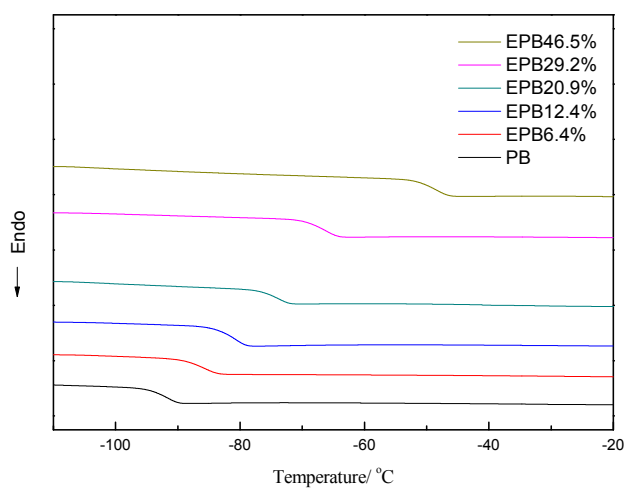

Fig. 2 DSC curves of PB and EPB.

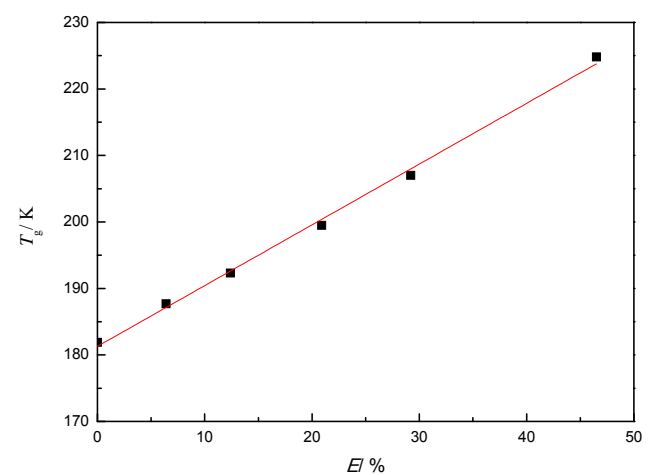

Fig. 3 Linear fitting between $T_{\mathrm{g}}$ and $E$.

The increase of the epoxidation degree meant that the polarity of EPB was enhanced, thus the compatibility of PLA and EPB could be improved. However, the increase of $T_{\mathrm{g}}$ weakened the flexibility of the molecular chain, which was disadvantageous for rubber toughing PLA. There must be a balance between these two contradictions.

\section{Rheological properties}

Dynamic rheological properties of pure PLA, PLA/PB and PLA/EPB were measured to discuss the processibility of the blends and the compatibility between two phases. The complex viscosities, $\eta^{*}$, of pure PLA and blends as a function of frequency, f, were shown in Fig. 4. It can be seen that pure PLA exhibited typical Newtonian behavior in the low frequency region and shear thinning from 
about $1 \mathrm{~Hz}$. The $\eta^{*}$ of the blends were substantially higher than that of pure PLA and increased with the epoxidation degree of EPB rose. The results were consistent with the reports about PLA/ENR blends [12]. The increase of the $\eta^{*}$ may be caused by strong interaction between epoxy groups of EPB and carboxyl and hydroxyl groups of PLA. The $\eta^{*}$ of the blends showed a slight shear thinning at lower frequencies $(<1 \mathrm{~Hz})$ and the shear thinning was more significant at higher frequencies $(1-100 \mathrm{~Hz})$, which indicated that the blends had high melt strength and good processing mobility at higher shear rate.

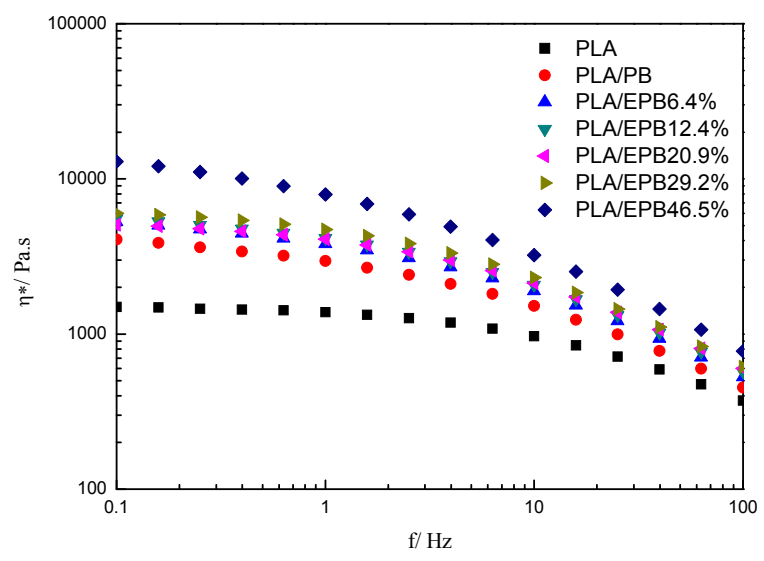

Fig. 4 Complex viscosity curves of pure PLA, PLA/PB and PLA/EPB.

The compatibility of polymer blends could be analyzed by Cole-Cole plot, representing by the relationship between the real $\left(\eta^{\prime}\right)$ and the imaginary $\left(\eta^{\prime \prime}\right)$ parts of $\eta^{*}[11,39]$. Generally, a smooth, semicircular shape of the plotted curves would suggest good compatibility and phase homogeneity in the melt, and any deviation from this shape shows a non-homogeneous dispersion and phase segregation due to incompatibility[40]. The Cole-Cole plot for PLA/PB and PLA/EPB at $190{ }^{\circ} \mathrm{C}$ is presented in Fig. 5. It was obvious that, for PLA/PB, PLA/EPB6.4\% and PLA/EPB12.4\%, a clear deviation from the semicircular curve was observed, which meant that rubber particles in the blends were distributed unevenly. The Cole-Cole plot showed a homogeneous dispersion in high epoxidation degree $(>20.9 \%)$ of EPB in the blends, as can be evidenced from the smooth semicircular shape of the plots. Using thermomechanical models, several authors have demonstrated that the morphology of an immiscible polymer blend is strongly dependent on two mechanisms occurring during the mixing, i.e. break-up and coalescence[41]. By increasing the epoxidation degree of EPB in the blends, the probability of the coalescence of EPB domains decreased, in other words, the shear forces that led to dispersion was strong when compared to the driving force toward demixing. As mentioned above, the compatibility of PLA/EPB blends was becoming better than PLA/PB. 


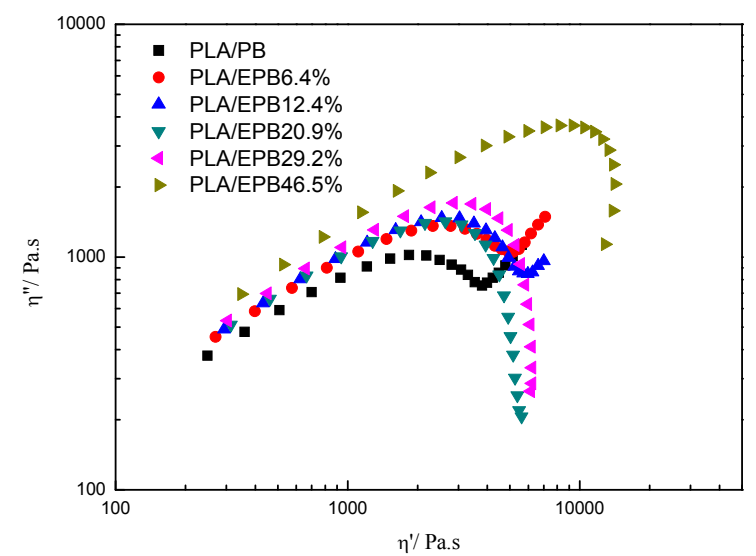

Fig. 5 Cole-Cole plot of PLA/PB and PLA/EPB.

The storage modulus, G', and loss modulus, G", with small-amplitude oscillatory frequency for pure PLA and the blends are given in Fig. 6. A homopolymer with narrow molecular weight distribution usually shows a characteristic terminal behavior of $G^{\prime}(\omega) \propto \omega^{2}[42]$. In our research, pure PLA deviated from the terminal behavior markedly $\left(\mathrm{G}^{\prime}(\omega) \propto \omega^{1.62}\right)$. The value was in consistent with the results reported in literature [11,43]. The $\mathrm{G}^{\prime}$ of all the blends deviated from the terminal behavior, $\mathrm{G}^{\prime}(\omega) \propto \omega^{0.99}$ for the PLA/PB and $\mathrm{G}^{\prime}(\omega) \square \omega^{1.17}$ for the PLA/EPB46.5\%. The partially miscible character of the blends might be the reason for the deviation [44]. The incorporation of PB or EPB affected the $\mathrm{G}^{\prime}$ and $\mathrm{G}^{\prime \prime}$ of the melts at all frequencies; they rose with the increase of the epoxidation degree of EPB, except that the PLA/EPB29.2\% decreased at low frequencies. The lower slope values and higher absolute values of dynamic modulus indicated the formation of entanglement structures in the blends. It is known that molecular chain PB was more flexible than that of PLA and was easier to entangle, thus, the entanglement density was higher than that of PLA, leading to high reversible elastic deformation $\left(\mathrm{G}^{\prime}\right)$ of the blends[43].
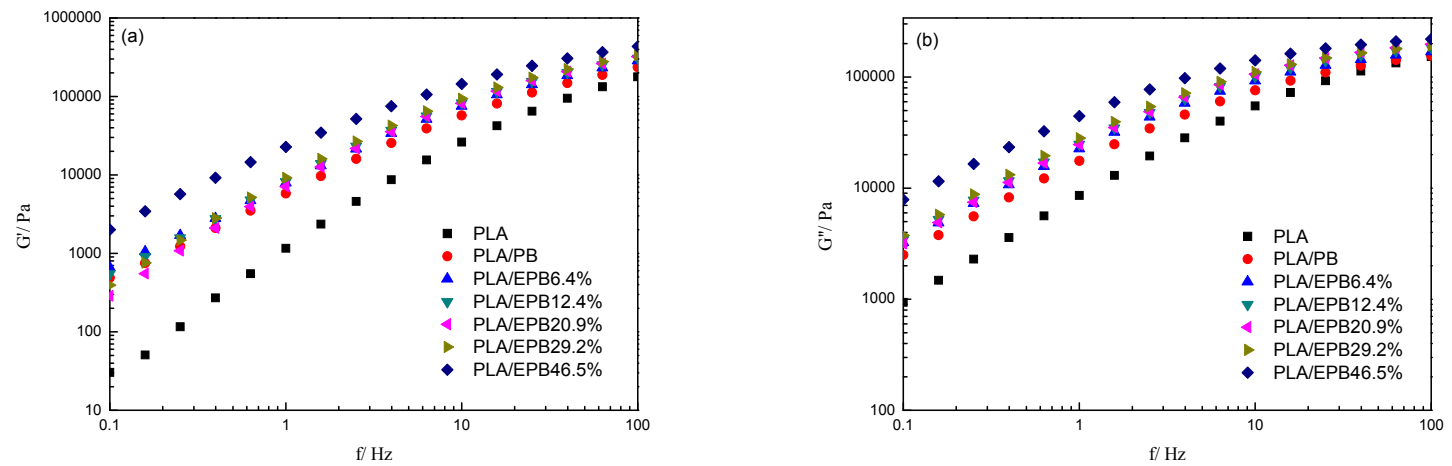

Fig. $6 G^{\prime}(a)$ and $G^{\prime \prime}(b)$ versus frequency for pure PLA, PLA/PB and PLA/EPB. 


\section{Morphology}

Typically, the rubber toughened plastic blend system is microscopic phase separated, the rubber particles perform as stress concentrators to absorb more fracture energy of brittle polymers, and finally improve the toughness of the blend $[35,45]$. The SEM images of cryofracture surfaces of PLA/PB, PLA/EPB20.9\% PLA/EPB46.5\% are presented in Fig. 7. The average particle diameter of all blends is listed in Table S1 (Supporting information). As seen from Fig. 7, typical sea-island morphology was obtained. All the blends exhibited microscopic phase separated structures and displayed relatively spherical rubber particles. It was found that PLA/PB possessed the largest rubber particle size and had a broader particle size distribution, which was caused by the poor compatibility between PB and PLA. In contrast, the rubber particles for PLA/EPB blends were becoming smaller and distributed uniformly with increasing epoxidation degree of EPB. The average particle size of the dispersed phase for PLA/EPB6.4\% or PLA/EPB12.4\% did not change so much compared to PLA/PB, but its distribution was becoming narrower. It was noteworthy that the particle size decreased sharply in high epoxidation degree $(>20.9 \%)$ of EPB in the blends. The dynamic rheological tests (as shown in Fig. 5) supported this conclusion, as they showed a smooth semicircular shape of Cole-Cole plot. Similar morphologies have been reported in many other reactive polymer blending system $[31,46]$. The size of the dispersed phase implied miscibility between the continuous and the dispersed phase. Theoretically, smaller particle indicated higher miscibility[47]. The smaller size of rubber particles in PLA/EPB indicated higher compatibility than $\mathrm{PLA} / \mathrm{PB}$.
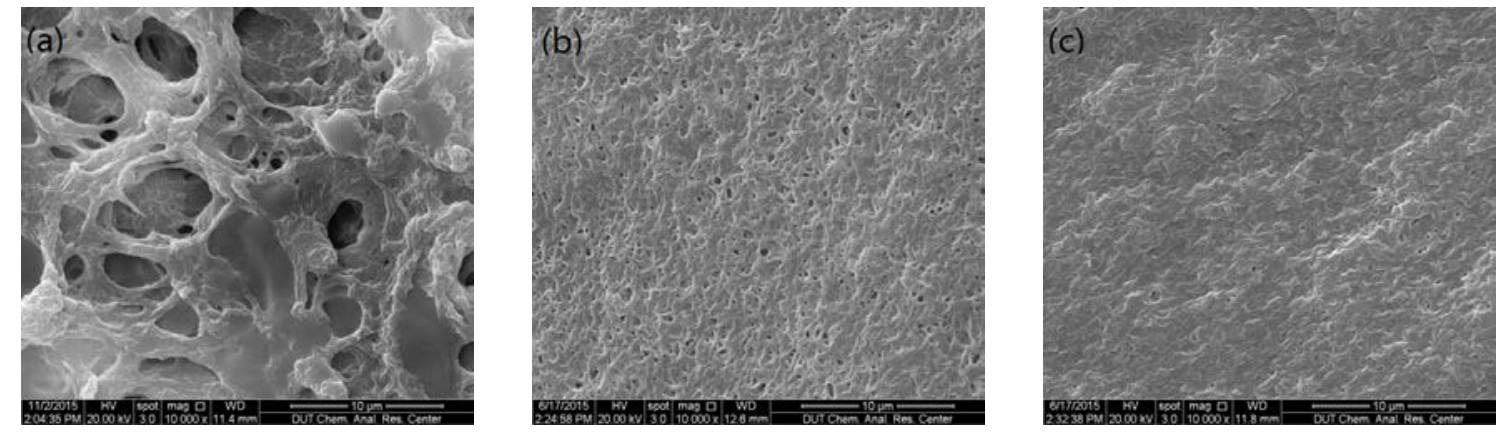

Fig.7 SEM images of cryofracture surfaces of (a) PLA/PB, (b) PLA/EPB20.9\%, (c)

PLA/EPB46.5\%.

The increase of the epoxidation degree meant that the polarity of EPB was enhanced, thus provided more compatibility providing smaller particle size of EPB in the blends. Nghia had investigated the compatibility of the PLA/ENR and concluded that the reaction occurred between the epoxy groups of ENR and the ester groups of PLA [36]. Tanrattanakul used ENR as toughening agent for nylon 6 , they mentioned that in situ graft copolymerization between PA6 and ENR 
occurred during melt blending [35]. In this study, the in situ graft copolymerization possibly occurred between the epoxy groups of EPB and the terminal carboxyl groups of PLA during melt blending, resulting in an improved interfacial compatibilization. The possible reaction between EPB and PLA is shown in scheme 2. Fig. 8 shows the absorption spectra of EPB20.9\% and PLA/EPB20.9\% in the range of 1000-800 $\mathrm{cm}^{-1}$. The absorption peak at $890 \mathrm{~cm}^{-1}$ and $812 \mathrm{~cm}^{-1}$ were attributed to the characteristic absorption of epoxy groups in the EPB. Noticeably, the absorption peak of epoxy groups was becoming weak in PLA/EPB blend, suggesting that PLA reacted with the epoxy groups of EPB during melt-blending. This may be one of the reasons for good interfacial adhesion.

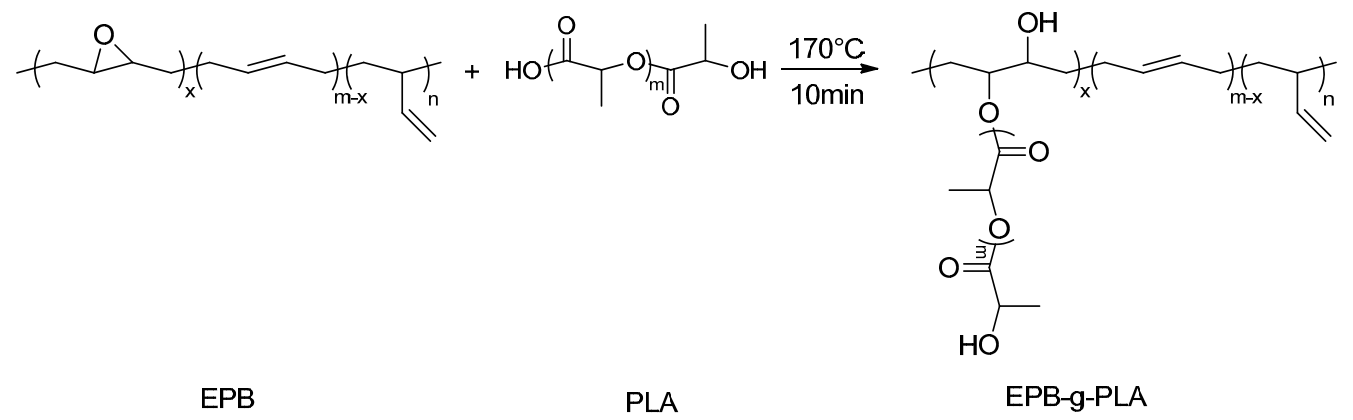

Scheme 2. The possible interfacial compatibilization reaction between EPB and PLA.

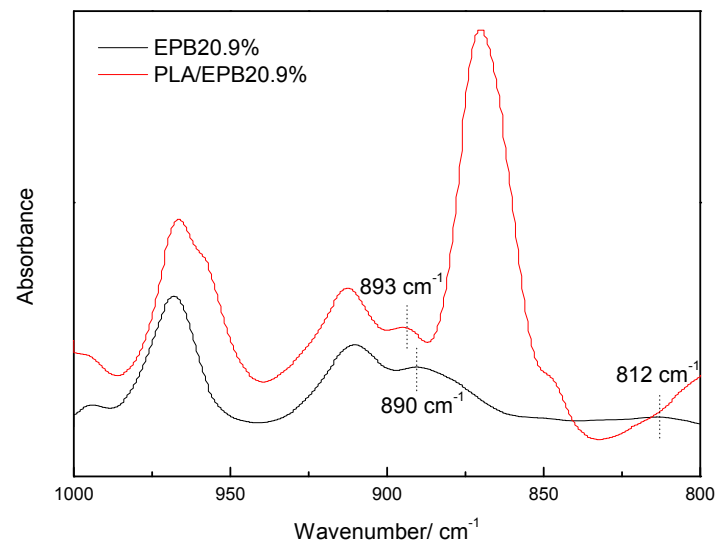

Fig. 8 FTIR absorption spectra of EPB20.9\% and PLA/EPB20.9\% blend.

The epoxidation degree of EPB was calculated using ${ }^{1} \mathrm{H}$ NMR spectra in this paper (Fig. 1 and Table 1). In order to obtain more quantitative data to assess the reaction of epoxy group, ${ }^{1} \mathrm{H}$ NMR spectra was also used to get the epoxidation degree of PLA/EPB blends ( $\left.E_{\text {blend }}\right)$. The ${ }^{1} \mathrm{H}$ NMR spectrum of PLA/EPB20.9\% was shown in Fig. S3 (Supporting information) and the detailed introduction for calculating the $E_{\text {blend }}$ was described in supporting information. The results were summarized in Table 2. It could be noted that the epoxidation degree had an obvious drop after 
blending for all the blends. This was an important proof that PLA reacted with the epoxy groups of EPB during melt blending.

Table 2 The epoxidation degree of PLA/EPB blends

\begin{tabular}{cc}
\hline Samples & $E_{\text {blend }}$ \\
\hline PLA/EPB $6.4 \%$ & $5.2 \%$ \\
PLA/EPB12.4\% & $6.1 \%$ \\
PLA/EPB20.9\% & $11.8 \%$ \\
PLA/EPB29.2\% & $15.5 \%$ \\
PLA/EPB46.5\% & $16.2 \%$ \\
\hline
\end{tabular}

\section{Mechanical properties}

In this work, the impact strength and the tensile properties were the primary focus of the mechanical properties. The impact resistance of the blends was given attention first. Fig. 9 illustrated the results of notched impact test of the blends. The impact strength of pure PLA was $29.9 \mathrm{~J} / \mathrm{m}$ and the impact strength increased to $74.1 \mathrm{~J} / \mathrm{m}$ after blending with PB, which was nearly 1.5 fold improved. Just as we thought, without interfacial compatibilization, the increments of impact toughness was not significant. As expected, EPB seemed to be a more suitable impact modifier which had a significant improvement on toughening PLA. PLA/EPB20.9\% showed the highest impact strength, $384.4 \mathrm{~J} / \mathrm{m}$, which was 12.9 fold compared to pure PLA. For the blend with the epoxidation degree of EPB less than $20.9 \%$, the impact strength of PLA blends was improved dramatically with the increase of the epoxidation degree. That was due to the epoxy group which had an obvious effect in enhancing compatibility of the blends. However, the impact strength decreased significantly if the epoxidation degrees of EPB continue to increase; for PLA/EPB46.5\%, the impact strength dropped to 229.2 $\mathrm{J} / \mathrm{m}$. 


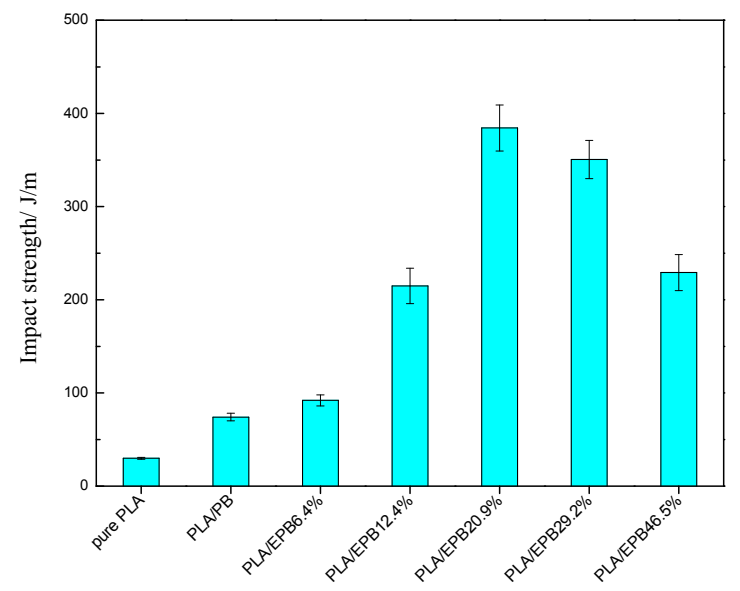

Fig. 9 Impact strength of pure PLA, PLA/PB and PLA/EPB.

Based on toughening mechanism, except for interfacial adhesion between rubber particles and matrix, size and shape of the rubber phase and toughening agent also play crucial roles in the efficiency of toughening. An optimum size region of $0.5-0.9 \mu \mathrm{m}$ has been reported in glassy PLA/polymerized soybean oil blend[29]. The morphology graphs showed that the particle size of the dispersed phase of PLA/EPB20.9\% was about $0.47 \mu \mathrm{m}$, while the particle size decreased to 0.18 $\mu \mathrm{m}$ in PLA/EPB46.5\%. For the blends with the epoxidation degree of EPB more than 20.9\%, it was assumed that the particle size of the rubber phase was too small for acting as a good toughening agent. In other words, the compatibility was too good to be a good toughening system. Besides, the toughening agent was also a crucial factor. Generally, the toughening agent with a lower $T_{\mathrm{g}}$ is preferred. As shown in Table 1, the $T_{\mathrm{g}}$ of the EPB increased slowly by increasing the epoxidation degree from 0 to $46.5 \%$. For example, the $T_{\mathrm{g}}$ of EPB46.5\% was $-48.4{ }^{\circ} \mathrm{C}, 42.9^{\circ} \mathrm{C}$ higher than $\mathrm{PB}$, which meant that EPB46.5\% had more structural rigidity than PB. Therefore, a suitable epoxidation degree was crucial to obtain the appropriate rubber particle size and good compatibility simultaneously.

Fig. 10 shows SEM micrographs of the impact-fractured surfaces of the samples which formed during Izod impact tests at room temperature. Pure PLA exhibited a smooth fracture without obvious stress whitening, indicating that pure PLA was brittle fractured. The impact fracture surface of PLA/EPB20.9\% was very rough and presented some domains with elongated rubber while a more smooth fracture was found in PLA/EPB46.5\% due to the high compatibility between PLA matrix and EPB46.5\%. Ishida et al. [48] and Juntuek et al. [49]observed two distinct phases in the PLA/rubber blends, many rubber particles were pulled out from the PLA matrix along with large voids being created during Izod impact testing. It was worth noting that there were no large voids presented in PLA/EPB20.9\% and PLA/EPB46.5\%, indicating that EPB was well compatible with 
PLA. Zhang et al.[12] observed a somewhat flocculated morphology in the PLA/ENR blends, noting that ENR was well compatible with PLA, and the blends were ductile ruptured. The impact-fractured surfaces of PLA/EPB were much familiar with the PLA/ENR blends.
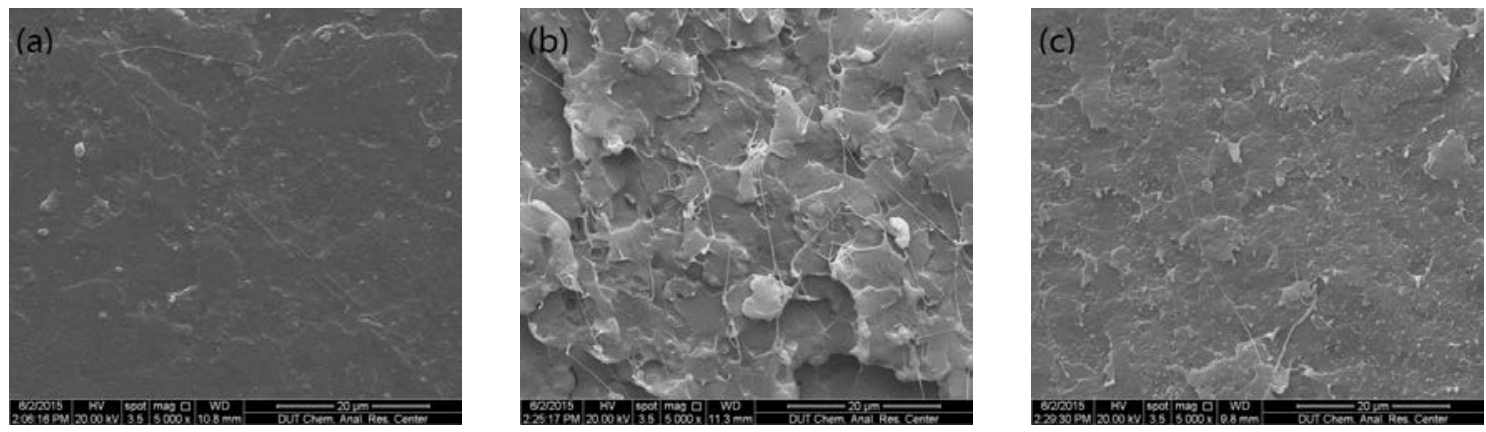

Fig. 10 SEM micrographs of Izod-impact-fractured surfaces for (a) pure PLA, (b) PLA/EPB20.9\%, (c) PLA/EPB46.5\%.

There is no doubt that the introduction of $\mathrm{PB}$ or EPB reduces the tensile strength of the blends while enhances the elongation as a result of low modulus of rubber phase. To realize the excellent toughness-strength balance, less flexible polymer component is necessary. In this study, the content of PB or EPB was fixed at $10 \mathrm{wt} \%$, which was favorable to the toughness-strength balance. Fig. 11 displays the tensile strength and elongation at break of pure PLA, PLA/PB and PLA/EPB. The PLA/EPB20.9\% exhibited the tensile strength as high as $53.6 \mathrm{MPa}$, which preserved as $77 \%$ of pure PLA. Meanwhile, its elongation increased from 3.5\% of pure PLA to $158.4 \%$. Moreover, it seemed that the tensile strength of PLA/EPB was not significantly influenced by the type of EPB, except for PLA/EPB46.5, decreased by 47\%. In Fig. 11(b), the elongation of blends was dramatically increased as compared to pure PLA, especially, the elongation increased from $3.5 \%$ of pure PLA to $189.1 \%$ of PLA/EPB29.2\%. Therefore, an excellent toughness-strength balance was achieved in PLA/EPB blends.
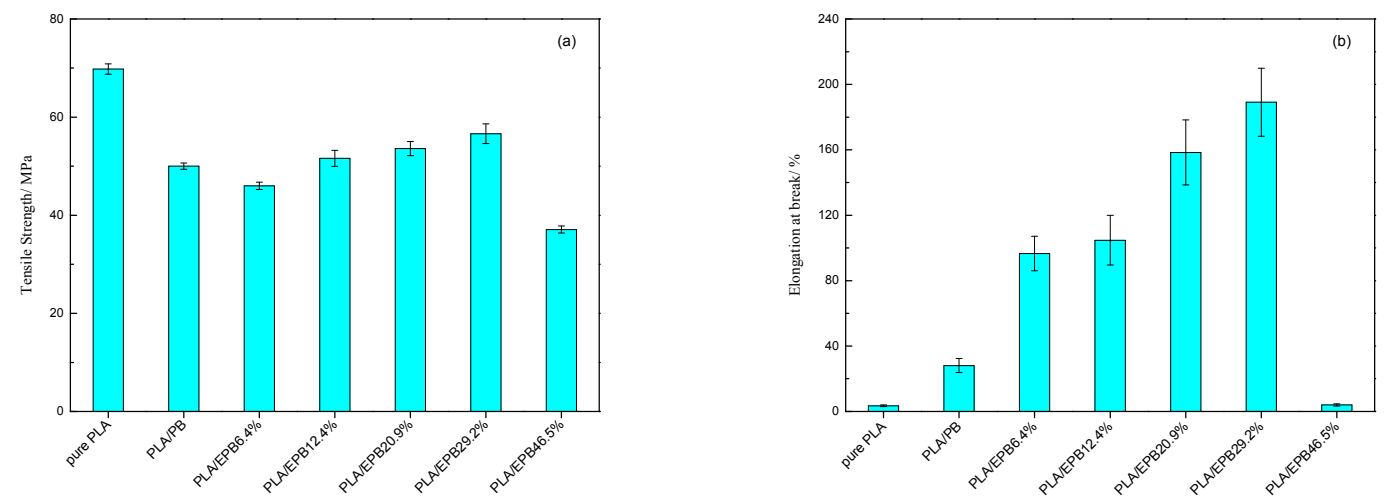

Fig. 11 Tensile strength (a) and elongation at break (b) of pure PLA, PLA/PB and PLA/EPB.

Sachiko Ishida believed that the difference in elongation was caused by that in the areas of the 
plastic deformation zone, where the materials showed whitening [48]. On the basis of this explanation, it was confirmed that the PLA/EPB showed larger plastic deformation zones near the fracture flank in comparison with PLA and PLA/PB. Unexpected, although the high compatibility in PLA/EPB46.5\%, the elongation was very poor and the sharply drop of the tensile strength was undesirable. The low tensile strength and elongation might be due to the low mobility of the chains caused by the strong interaction between PLA and EPB46.5\%, which might led to the formation of too much cross-linked structure.

\section{Thermal properties}

The initial states of the pure PLA, PLA/PB and PLA/EPB were studied by DSC. Fig. 12(a) illustrates the DSC thermograms from the first heating scan and the data results are listed in Table 3(a). The $T_{\mathrm{g}}$ of pure PLA was $61.5^{\circ} \mathrm{C}$, and a large cold crystallization exotherm appeared starting at about $90{ }^{\circ} \mathrm{C}$ and ending at about $120{ }^{\circ} \mathrm{C}$, followed by its melting endotherm at approximately $170{ }^{\circ} \mathrm{C}$. As demonstrated in Fig. 12(a) and Table 3(a), the $T_{\mathrm{g}}$ of PLA/PB and PLA/EPB was around $61-64{ }^{\circ} \mathrm{C}$, which was same as pure PLA. In each thermogram, there was a very large cold crystallization exotherm, the area of which was quite similar to that of the melting endotherm. The initial crystallinity of all the samples were below $10 \%$, which suggested that the PLA component in each blend was mostly in the amorphous state.
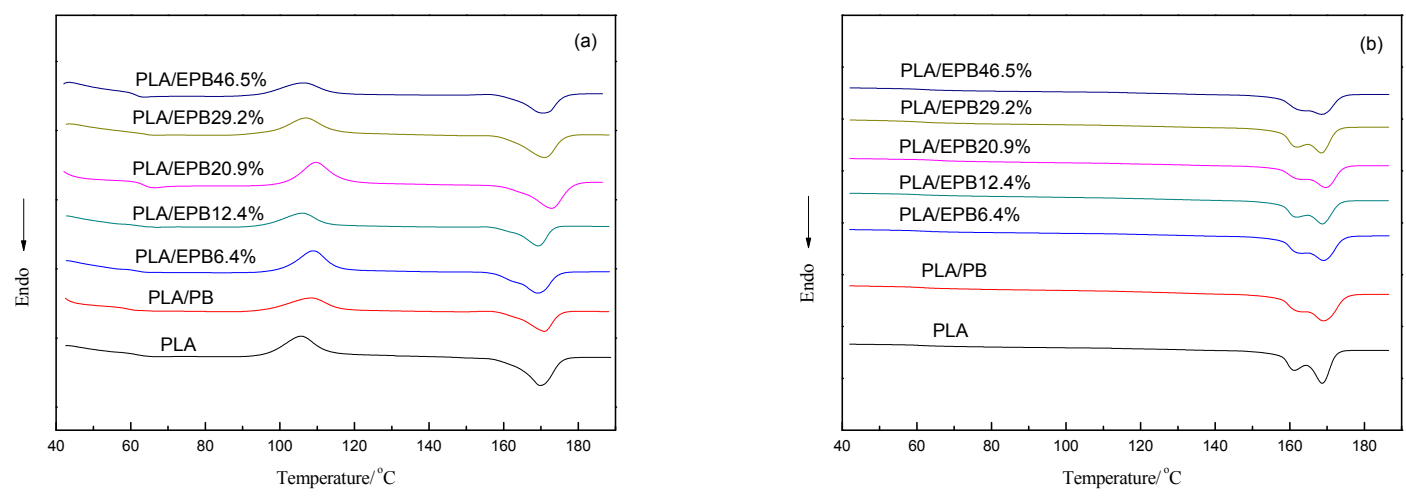

Fig. 12 DSC curves of pure PLA, PLA/PB and PLA/EPB: (a) first heating scan, (b) second heating scan after annealed at $105^{\circ} \mathrm{C}$ for $60 \mathrm{~min}$.

Table 3 Thermal properties and the crystallinity of pure PLA, PLA/PB and PLA/EPB during (a) first heating, (b) second heating after annealed at $105^{\circ} \mathrm{C}$ for $60 \mathrm{~min}$.

(a) First heating

\begin{tabular}{cccccc}
\hline Samples & $T_{\mathrm{g}},{ }^{\circ} \mathrm{C}$ & $T_{\mathrm{c}},{ }^{\circ} \mathrm{C}$ & $T_{\mathrm{m}},{ }^{\circ} \mathrm{C}$ & $\Delta H_{\mathrm{m}}, \mathrm{J} / \mathrm{g}$ & $\% X \mathrm{c}$ \\
\hline PLA & 61.5 & 105.7 & 169.8 & 0.5 & 0.5
\end{tabular}




\begin{tabular}{|c|c|c|c|c|c|c|}
\hline $\mathrm{PLA} / \mathrm{PB}$ & 61.3 & 108.0 & & 169.2 & 0.8 & 0.9 \\
\hline PLA/EPB6.4\% & 62.2 & 109.0 & & 169.1 & 6.2 & 7.4 \\
\hline PLA/EPB12.4\% & 63.7 & 106.0 & & 169.3 & 1.4 & 1.7 \\
\hline PLA/EPB20.9\% & 63.6 & 109.7 & & 172.9 & 4.4 & 5.2 \\
\hline PLA/EPB29.2\% & 64.3 & 107.0 & & 171.0 & 0.9 & 1.1 \\
\hline PLA/EPB46.5\% & 61.4 & 106.2 & & 170.6 & 1.8 & 2.1 \\
\hline \multicolumn{7}{|c|}{ (b) Second heating after annealed at $105^{\circ} \mathrm{C}$ for $60 \mathrm{~min}$} \\
\hline Samples & $T_{\mathrm{m} 1},{ }^{\circ} \mathrm{C}$ & & $T_{\mathrm{m} 2},{ }^{\circ} \mathrm{C}$ & & $\Delta H_{\mathrm{m}}, \mathrm{J} / \mathrm{g}$ & $\% X_{\mathrm{c}}$ \\
\hline PLA & 161.3 & & 168.7 & & 46.1 & 49.3 \\
\hline $\mathrm{PLA} / \mathrm{PB}$ & 163.4 & & 169.0 & & 41.3 & 49.0 \\
\hline PLA/EPB6.4\% & 163.2 & & 169.1 & & 40.2 & 47.7 \\
\hline PLA/EPB12.4\% & 161.9 & & 168.7 & & 40.5 & 48.1 \\
\hline PLA/EPB20.9\% & 162.9 & & 169.6 & & 40.0 & 47.5 \\
\hline PLA/EPB29.2\% & 161.9 & & 168.5 & & 41.2 & 48.9 \\
\hline PLA/EPB46.5\% & 163.8 & & 168.5 & & 37.7 & 44.8 \\
\hline
\end{tabular}

The crystallization properties of pure PLA, PLA/PB and PLA/EPB were also studied in detail. Fig. 12(b) illustrates the DSC thermograms from the second heating scan and the data results are listed in Table 3(b). Unlike the first heating scan, there was no obvious glass transition peak or cold crystallization exotherm presented in the second heating scan after being annealed at $105{ }^{\circ} \mathrm{C}$ for isothermal crystallization for $60 \mathrm{~min}$, which meant that the samples crystallized during annealing procedure. All the samples revealed two melting peaks. The melting endotherm at higher temperature was more prominent than that at lower temperature. The melting peak at higher temperature corresponded to more perfect crystalline form than that at lower temperature [50, 51]. The crystallinity for all the samples was around $44.8-49.3 \%$, which was much higher than that of the initial state. The incorporation of EPB or PB seemed have no significant effect on the crystallinity of PLA in the blends. The results were similar to that of PLA/ENR blends reported by Zhang [12].

In this blending system, the glass transition of the rubber phase could not be detected by DSC due to the very low content $(10 \mathrm{wt} \%)$ in the blends. However, DMA is a good choice to determine the weak glass transition for these blends. Damping factors ( $\tan \delta$ ) obtained from DMA measurements for PLA/PB and PLA/EPB are shown in Fig. 13 and Table 4. The $T_{\mathrm{g}}$ of the PLA matrix was around $70{ }^{\circ} \mathrm{C}$, as indicated by the tan $\delta$ peak at higher temperature $\left(T_{\mathrm{g} 2}\right)$, which was 
higher than the results determined by DSC (as shown in Table 3). All the blends in this study exhibited a second weak damping peak between $-110{ }^{\circ} \mathrm{C}$ to $0{ }^{\circ} \mathrm{C}$ attributed to the glass transition of the rubber phase $\left(T_{\mathrm{g} 1}\right)$ [25]. Compared to the $T_{\mathrm{g}}$ of EPB (as shown in Table 1), $T_{\mathrm{g} 1}$ was much higher. Furthermore, the differences $\left(\Delta T_{\mathrm{g} 1}, T_{\mathrm{g}, \mathrm{EPB}}-T_{\mathrm{g} 1}\right)$ became bigger with the epoxidation degree rose. PLA/EPB46.5\% led to a higher $\Delta T_{\mathrm{g} 1}$ than others because it had more epoxy groups available for the reactions with the carboxyl groups of PLA, thus more graft-copolymer was produced affecting the rubber phase.

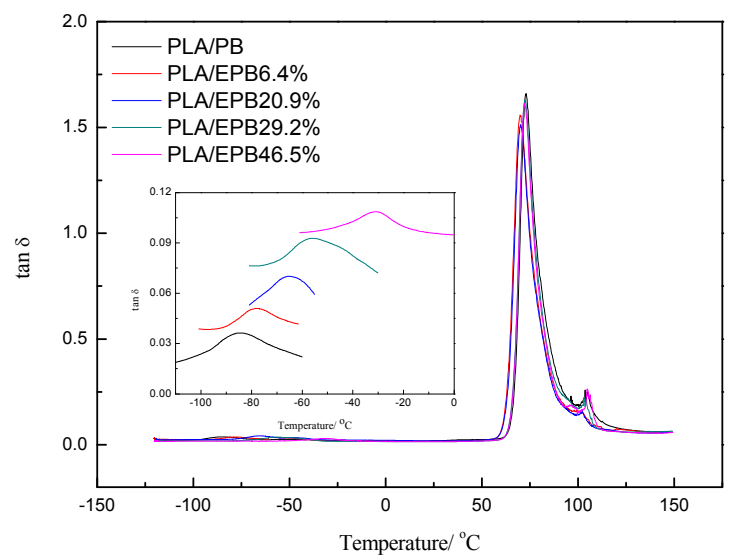

Fig. 13 Dependence of damping factor $(\tan \delta$ ) on temperature for PLA/PB and PLA/EPB.

Table $4 T_{\mathrm{g}}$ for PLA/PB and PLA/EPB determined by DMA.

\begin{tabular}{cccc}
\hline Samples & $T_{\mathrm{g} 1,}{ }^{\circ} \mathrm{C}$ & $T_{\mathrm{g} 2},{ }^{\circ} \mathrm{C}$ & $\Delta T_{\mathrm{g} 1},{ }^{\circ} \mathrm{C}^{\mathrm{a}}$ \\
\hline PLA/PB & -84.8 & 73.0 & 6.5 \\
PLA/EPB6.4\% & -78.9 & 69.9 & 6.6 \\
PLA/EPB20.9\% & -64.8 & 70.2 & 8.9 \\
PLA/EPB29.2\% & -56.3 & 72.4 & 9.9 \\
PLA/EPB46.5\% & -32.0 & 72.4 & 16.4
\end{tabular}

${ }^{\mathrm{a}} \Delta T_{\mathrm{g} 1}=T_{\mathrm{g}, \text { EPB }}(\mathrm{EPB}$, as shown in Table 1$)-T_{\mathrm{g} 1}$

The glass transition temperatures of the blends were of particular interest to determine whether the two components were miscible or immiscible[52]. The $T_{\mathrm{g}}$ of each polymeric component does not change in completely immiscible mixtures, generally perfect miscible blends exhibit a single broad $T_{\mathrm{g}}$ located between the $T_{\mathrm{g}} \mathrm{S}$ of the individual components of the blend, while the $T_{\mathrm{g}}$ of each polymeric component comes to each other for partially miscible mixtures. The final $T_{\mathrm{g}}$ of perfect miscible binary blends can be predicted by the well-known Fox equation as a function of the weight fraction of the two polymeric components and their $T_{\mathrm{g}} \mathrm{S}$, respectively[53]. According to Fox 
equation, $T_{\mathrm{g}}$ for PLA/EPB would be a value close to that of pure PLA if PLA and EPB were perfect miscible. However, DMA results showed that all the PLA/EPB blends had two glass transitions, which implied that the two components were not a perfect miscible mixture in the blends. Compared to the $T_{\mathrm{g}}$ of EPB (as shown in Table 1), $T_{\mathrm{g} 1}$ (the $T_{\mathrm{g}}$ of the rubber phase) was much higher. It could be inferred that much of EPB had graft reaction with PLA in the melt blending. Graft-copolymer was created at the interface, resulting in a higher $T_{\mathrm{g} 1}$. However, the $T_{\mathrm{g}}$ of PLA matrix remained similar to that of pure PLA, and no remarkable effect was observed by changing epoxidation degree of EPB. This was an observation suggesting that only a small part of PLA involved in the grafting reaction, and PLA matrix and rubber phase still existed in the form of phase separation. The SEM micrographs (as shown in Fig. 7) supported this conclusion, as they showed a clear phase separated morphology with impact modifier dispersed in PLA matrix. Similar results were also found in other similar systems[11, 21, 33, 54-56].

As we known, the onset thermal degradation temperature of PB is much higher than that of PLA, and the incorporation of EPB or PB may affect the thermal degradation of the blends. The thermal degradation behavior of PLA/EPB, PLA/PB and PLA determined by TGA in nitrogen is shown in Fig. 14, and the data are illustrated in Table 5. Pure PLA evidenced a one-stage weight loss during thermal decomposition, while PLA/PB and PLA/EPB evidenced a two-stage weight loss. The weight loss of $320{ }^{\circ} \mathrm{C}$ to $420{ }^{\circ} \mathrm{C}$ was attributed to the PLA degradation, and $420{ }^{\circ} \mathrm{C}$ to $520{ }^{\circ} \mathrm{C}$ was attributed to the degradation of PB or EPB. The $T_{\mathrm{d} 5 \%}$ of the blends was around $334.8^{\circ} \mathrm{C}$ to $338.7^{\circ} \mathrm{C}$, which was close to $T_{\mathrm{d} 5 \%}$ of pure PLA $\left(336.5^{\circ} \mathrm{C}\right)$, and the differences of $T_{\mathrm{d} 0}$ and $T_{\mathrm{d} 1}$ between these samples were small, indicating that the effect of PB or EPB on the thermal degradation of PLA was not obvious. The $T_{\mathrm{d} 2}$ of PLA/PB was $466.1{ }^{\circ} \mathrm{C}$, with the increase of the epoxidation degree of EPB, the $T_{\mathrm{d} 2}$ of PLA/EPB decreased obviously. For PLA/EPB46.5\%, the $T_{\mathrm{d} 2}$ of was $448.2{ }^{\circ} \mathrm{C}$, decreased by $17.9{ }^{\circ} \mathrm{C}$ compared with PLA/PB. That was mainly due to the fact that graft-copolymer was created at the interface in the blending process. Obviously, the effect of graft-copolymer on the thermal stability of EPB was higher than on PLA. 


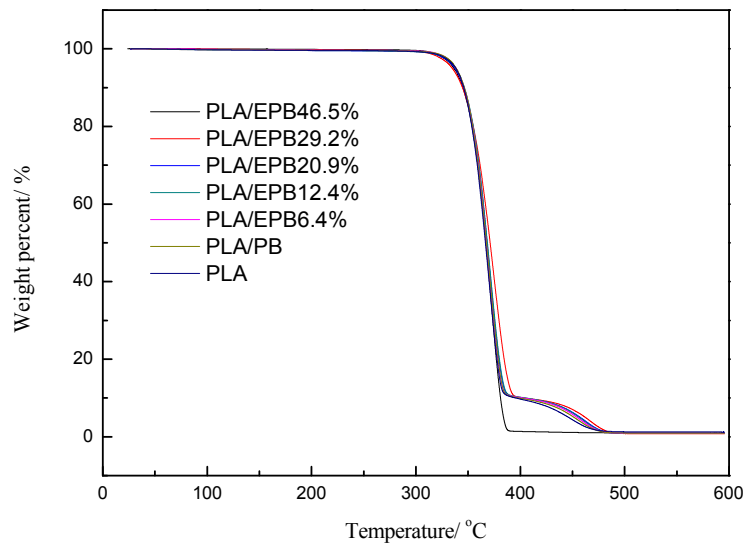

Fig. 14 TGA curves of pure PLA, PLA/PB and PLA/EPB.

Table 5 Decomposition temperatures of pure PLA, PLA/PB and PLA/EPB determined from the TGA curves.

\begin{tabular}{ccccc}
\hline Samples & $T_{\mathrm{d} 0},{ }^{\circ} \mathrm{C}$ & $T_{\mathrm{d} 5 \%},{ }^{\circ} \mathrm{C}$ & $T_{\mathrm{d} 1},{ }^{\circ} \mathrm{C}$ & $T_{\mathrm{d} 2},{ }^{\circ} \mathrm{C}$ \\
\hline Pure PLA & 340.0 & 336.5 & 371.5 & - \\
PLA/PB & 337.1 & 334.8 & 374.6 & 466.1 \\
PLA/EPB6.4\% & 339.5 & 337.6 & 371.0 & 461.2 \\
PLA/EPB12.4\% & 340.1 & 338.2 & 371.1 & 460.0 \\
PLA/EPB20.9\% & 340.2 & 338.2 & 369.9 & 457.9 \\
PLA/EPB29.2\% & 339.5 & 338.7 & 370.1 & 455.4 \\
PLA/EPB46.5\% & 337.9 & 338.2 & 369.3 & 448.2
\end{tabular}

\section{Conclusions}

EPB with different epoxidation degree were prepared by reacting polybutadiene with peroxide and successfully used as toughening agent for PLA. An excellent toughness-strength balance was achieved in PLA/EPB blends with low rubber content (10 wt \%). For PLA/EPB20.9\%, the impact strength and elongation increased for 13 times and 45 times respectively comparing to that of pure PLA, and the tensile strength could preserve as $77 \%$ of pure PLA. The blends showed good compatibility and phase homogeneity for EPB with high epoxidation degree $(\geq 20.9 \%)$ in the blends. All the blends exhibited microscopic phase separated structures and displayed relatively spherical rubber particles in SEM graphs. The incorporation of EPB greatly enhanced the impact strength and the elongation of the blends, most likely attributed to the good compatibility and appropriate rubber 
particle size in the PLA matrix. All the blends were amorphous after melt blending, and they were crystalline and revealed two melting peaks in the thermograms after being annealed at $105{ }^{\circ} \mathrm{C}$ for 60 min. The incorporation of PB or EPB had no significant effect on the glass transition or crystallization of PLA in the blends.

\section{Acknowledgments}

This work was financially supported by National Program on Key Basic Research Program of China (973 Program No. 2015CB654700 (2015CB654701) and National Science Foundation of China (No. 21034001, and 21174021).

\section{References:}

1. Shibata M, Teramoto N and Inoue Y. Polymer 2007;48(9):2768-2777.

2. Xu H, Teng C and Yu M. Polymer 2006;47(11):3922-3928.

3. Rasal RM, Janorkar AV and Hirt DE. Progress in Polymer Science 2010;35(3):338-356.

4. Wang Y and Hillmyer MA. Macromolecules 2000;33(20):7395-7403.

5. Chen Y, Yuan D and Xu C. ACS Applied Materials \& Interfaces 2014;6(6):3811-3816.

6. Bitinis N, Verdejo R, Bras J, Fortunati E, Kenny JM, Torre L, and López-Manchado MA. Carbohydrate Polymers 2013;96(2):611-620.

7. Song W, Liu H, Chen F, and Zhang J. Polymer 2012;53(12):2476-2484.

8. Liu H, Guo L, Guo X, and Zhang J. Polymer 2012;53(2):272-276.

9. Ma P, Hristova-Bogaerds DG, Goossens JGP, Spoelstra AB, Zhang Y, and Lemstra PJ. European Polymer Journal 2012;48(1):146-154.

10. Odent J, Leclère P, Raquez J, and Dubois P. European Polymer Journal 2013;49(4):914-922.

11. Meng B, Deng J, Liu Q, Wu Z, and Yang W. European Polymer Journal 2012;48(1):127-135.

12. Zhang C, Wang W, Huang Y, Pan Y, Jiang L, Dan Y, Luo Y, and Peng Z. Materials \& Design 2013;45:198-205.

13. Bitinis N, Fortunati E, Verdejo R, Armentano I, Torre L, Kenny JM, and López-Manchado MÁ. Applied Clay Science 2014;93-94:78-84.

14. Zhang C, Man C, Pan Y, Wang W, Jiang L, and Dan Y. Polymer International 2011;60(10):1548-1555.

15. Zhang C, Huang Y, Luo C, Jiang L, and Dan Y. Journal of Polymer Research 2013;20(4):121.

16. Pongtanayut K, Thongpin C and Santawitee O. Energy Procedia 2013;34:888-897.

17. Noda I, Satkowski MM, Dowrey AE, and Marcott C. Macromolecular Bioscience 2004;4(3):269-275.

18. Li L, Huang W, Wang B, Wei W, Gu Q, and Chen P. Polymer 2015;68:183-194.

19. Broz M. Biomaterials 2003;24(23):4181-4190.

20. Chen CC, Chueh JY, Tseng H, Huang HM, and Lee SY. Biomaterials 2003;24(7):1167-1173.

21. Ojijo V and Ray SS. Polymer 2015;80:1-17.

22. Anderson KS, Lim SH and Hillmyer MA. Journal of Applied Polymer Science 2003;89(14):3757-3768.

23. Hashima K, Nishitsuji S and Inoue T. Polymer 2010;51(17):3934-3939.

24. Li Y and Shimizu H. European Polymer Journal 2009;45(3):738-746.

25. Liu H, Song W, Chen F, Guo L, and Zhang J. Macromolecules 2011;44(6):1513-1522.

26. Ojijo V, Sinha Ray S and Sadiku R. ACS Applied Materials \& Interfaces 2013;5(10):4266-4276.

27. Ma P, Spoelstra AB, Schmit P, and Lemstra PJ. European Polymer Journal 2013;49(6):1523-1531.

28. Su Z, Li Q, Liu Y, Hu G, and Wu C. European Polymer Journal 2009;45(8):2428-2433.

29. Robertson ML, Chang K, Gramlich WM, and Hillmyer MA. Macromolecules 2010;43(4):1807-1814. 
30. Kelly S. Anderson KMSM. Polymer Reviews 2008;48(1):85-108.

31. Wu M, Wu Z, Wang K, Zhang Q, and Fu Q. Polymer 2014;55(24):6409-6417.

32. Huang Y, Zhang C, Pan Y, Zhou Y, Jiang L, and Dan Y. Polymer Degradation and Stability 2013;98(5):943-950.

33. Jaratrotkamjorn R, Khaokong C and Tanrattanakul V. Journal of Applied Polymer Science 2012;124(6):5027-5036.

34. Huang Y, Zhang C, Pan Y, Wang W, Jiang L, and Dan Y. Journal of Polymers and the Environment 2013;21(2):375-387.

35. Tanrattanakul V, Sungthong N and Raksa P. Polymer Testing 2008;27(7):794-800.

36. Nghia PT, Siripitakchai N, Klinklai W, Saito T, Yamamoto Y, and Kawahara S. Journal of Applied Polymer Science 2008;108(1):393-399.

37. Zeng J, Li K and Du A. RSC Advances 2015;5(41):32546-32565.

38. Gao Q, Wang Y, Ren Y, and Li Y. Macromolecular Chemistry and Physics 2013;214(15):1677-1687.

39. Cho K, Yang J and Park CE. Polymer 1998;39(14):3073-3081.

40. Joshi M, Butola BS, Simon G, and Kukaleva N. Macromolecules 2006;39(5):1839-1849.

41. Dell'Erba R, Groeninckx G, Maglio G, Malinconico M, and Migliozzi A. Polymer 2001;42(18):7831-7840.

42. Sinha Ray S, Yamada K, Okamoto M, and Ueda K. Polymer 2003;44(3):857-866.

43. Gu S, Zhang K, Ren J, and Zhan H. Carbohydrate Polymers 2008;74(1):79-85.

44. Kapnistos M, Hinrichs A, Vlassopoulos D, Anastasiadis SH, Stammer A, and Wolf BA. Macromolecules 1996;29(22):7155-7163.

45. Giaconi GF, Castellani L, Maestrini C, and Riccò T. Polymer 1998;39(25):6315-6324.

46. Bhadane PA, Tsou AH, Cheng J, and Favis BD. Macromolecules 2008;41(20):7549-7559.

47. Chumeka W, Tanrattanakul V, Pilard J, and Pasetto P. Journal of Polymers and the Environment 2013;21(2):450-460.

48. Ishida S, Nagasaki R, Chino K, Dong T, and Inoue Y. Journal of Applied Polymer Science 2009;113(1):558-566.

49. Juntuek P, Ruksakulpiwat C, Chumsamrong P, and Ruksakulpiwat Y. Journal of Applied Polymer Science 2012;125(1):745-754.

50. Sarasua J, Prud'Homme R and Wisniewski M. Macromolecules;31(12):3895-3905.

51. Zhang J, Tashiro K, Tsuji H, and Domb AJ. Macromolecules 2008;41(4):1352-1357.

52. Afrifah KA and Matuana LM. Macromolecular Materials and Engineering 2010;295(9):802-811.

53. G FT. Bulletin of the american physical society 1956;1(2):123.

54. He Y, Zeng J, Liu G, Li Q, and Wang Y. RSC Advances 2014;4(25):12857-12866.

55. Tham WL, Poh BT, Mohd Ishak ZA, and Chow WS. Journal of Applied Polymer Science 2016;133(3):42850.

56. Li X, Kang H, Shen J, Zhang L, Nishi T, Ito K, Zhao C, and Coates P. Polymer 2014;55(16):4313-4323. 


\section{Graphical Abstract}
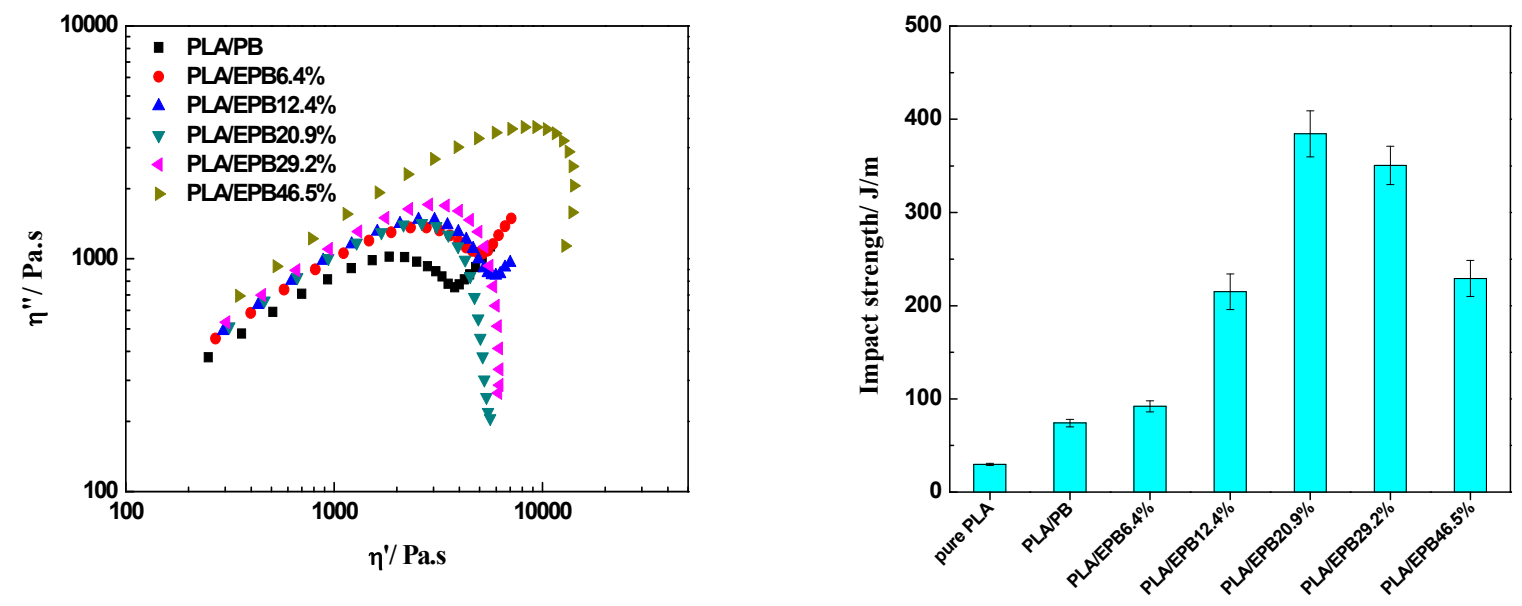